\title{
Evan Haefeli, New Netherland and the Dutch Origins of American Religious Liberty
}

Philadelphie, University of Pennsylvania Press, coll. « Early American Studies », 2012, XVI-355 p.

Cartes, bibliographie, index.

\section{Willem Frijhoff}

\section{(2) OpenEdition}

\section{Journals}

Édition électronique

URL : http://journals.openedition.org/assr/26445

DOI : 10.4000 /assr.26445

ISSN : $1777-5825$

Éditeur

Éditions de l'EHESS

\section{Édition imprimée}

Date de publication : 31 décembre 2014

Pagination : 208

ISBN : 978-2-7132-2467-6

ISSN : 0335-5985

Référence électronique

Willem Frijhoff, "Evan Haefeli, New Netherland and the Dutch Origins of American Religious Liberty », Archives de sciences sociales des religions [En ligne], 168 | 2014, mis en ligne le 29 avril 2015, consulté le 22 septembre 2020. URL : http://journals.openedition.org/assr/26445 ; DOI : https://doi.org/ 10.4000 /assr.26445

Ce document a été généré automatiquement le 22 septembre 2020.

(c) Archives de sciences sociales des religions 


\section{Evan Haefeli, New Netherland and the Dutch Origins of American Religious Liberty}

Philadelphie, University of Pennsylvania Press, coll. « Early American Studies », 2012, XVI-355 p.

Cartes, bibliographie, index.

Willem Frijhoff

\section{RÉFÉRENCE}

Evan Haefeli, New Netherland and the Dutch Origins of American Religious Liberty, Philadelphie, University of Pennsylvania Press, coll. «Early American Studies », 2012, XVI-355 $\mathrm{p}$.

Cartes, bibliographie, index. 
1 La liberté religieuse fait partie des valeurs de base, estimées fondatrices, de la société américaine, mais l'interprétation de ses origines et de sa portée dans l'histoire a connu bien des vicissitudes. Les « pères de la Constitution» Thomas Jefferson et James Madison ont été avancés comme ses premiers champions lors de la genèse des États-Unis en tant qu'État indépendant, mais d'autres la font remonter à William Penn, voire Roger Williams, au XVII siècle. Le renouveau récent de l'intérêt porté à la diversité des populations qui ont constitué la société américaine, au-delà des vieux poncifs sur le puritanisme anglais fondateur, a tout particulièrement remis en valeur l'apport spécifique des Néerlandais. Ils étaient présents sur le territoire américain depuis le premier voyage d'exploration de Henri Hudson au

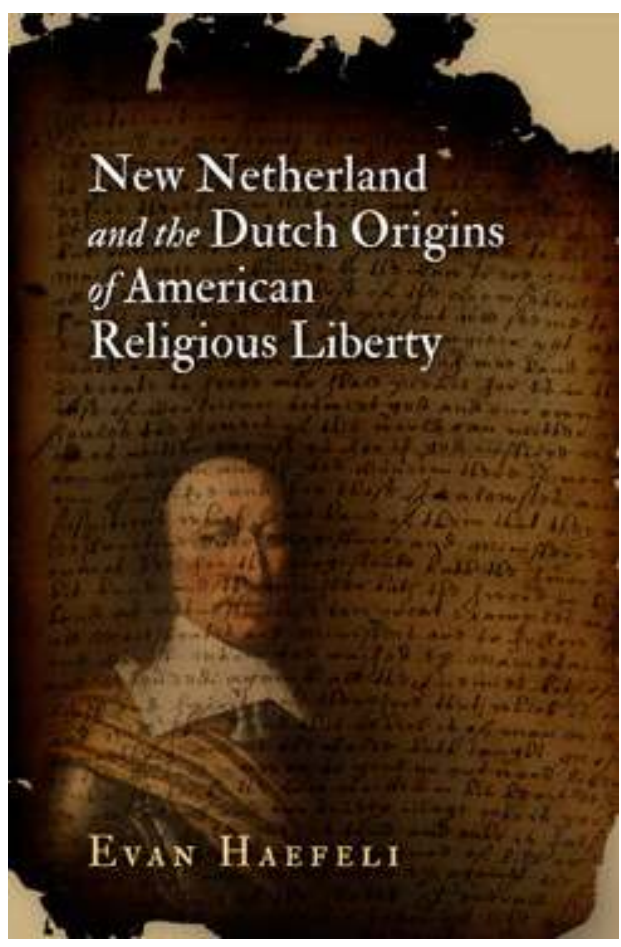
service de la Compagnie des Indes Orientales néerlandaise vers Manhattan en 1609, puis politiquement en tant que colonisateurs sous le régime de la Compagnie des Indes Occidentales depuis les années 1620 jusqu'à la première conquête, encore éphémère, de la colonie de Nouvelle Néerlande (sous le gouvernement de Petrus Stuyvesant) par les Anglais en 1664, à cela s'ajoute le passage final sous le régime anglais en 1674 qui amena en même temps le changement définitif du nom du territoire central de la colonie et de sa capitale Nouvelle Amsterdam en New York.

2 Depuis le début, et contrairement à la colonie anglaise voisine du Massachusetts, la Nouvelle Néerlande avait été un creuset de groupes d'immigrés de différentes origines et religions à l'image de sa société mère en Europe: outre les réformés, on y dénombrait des luthériens, mennonites et catholiques, puis des Juifs et quakers et même quelques musulmans, sans parler des religions plus ou moins syncrétistes des populations noires venues des ex-colonies portugaises et, bien sûr, des cultes indigènes que les Néerlandais signalaient bien dans leurs descriptions du pays mais dont ils ne comprenaient rien. Comme le régime politique et législatif correspondait à ce qui était décrété en Hollande, la colonie avait formellement une seule religion publique, l'Église réformée, mais dans la vie de tous les jours une grande permissivité envers les autres confessions était de règle jusqu'au régime de Stuyvesant (nommé directeur général en 1646), qui, lui-même fils d'un pasteur frison, était un calviniste pur et dur et un gouverneur très autoritaire. Après le passage définitif du pouvoir aux Anglais qui au cours des décennies précédentes avaient déjà discrètement pris leur place dans la colonie, celle-ci se retrouvait donc en présence de deux communautés bien marquées, parfois diamétralement opposées (l'une dominée par les Néerlandais, l'autre par les Anglais), de deux régimes législatifs fort différents régis respectivement par le droit romain et néerlandais d'une part, et par la common law d'autre part; soit également deux statuts confessionnels privilégiés, semi-monopolistiques, l'un pour l'Église 
réformée néerlandaise au sein de la communauté des anciens occupants, l'autre au profit de l'Église anglicane.

3 Ce qui caractérisait les deux partis était un certain degré de connivence de fait variable selon la communauté, les responsables, la conjoncture politique et l'époque pour des opinions qui déviaient des positions de l'Église publique, une forme de tolérance religieuse qui n'était pas vraiment une liberté formelle mais permettait de s'accommoder des interdits et de la répression officielle. Cette permissivité religieuse ou connivence confessionnelle était caractéristique de la société hollandaise européenne construite sur une diversité d'opinions politiques et religieuses, en dépit du caractère formellement réformé de l'État néerlandais. Elle trouvait donc tout naturellement son corollaire en Amérique. Dans une perspective révisionniste, certains auteurs, intellectuels ou historiens américains concluent depuis quelque temps assez sommairement à l'existence en Nouvelle Néerlande d'une société fondée structurellement sur la tolérance qui aurait, de ce fait, marquée la société américaine jusqu'à nos jours du sceau de la liberté religieuse. Le récit des origines spécifiques se déplace donc des colonies anglaises vers la colonie néerlandaise (New York, New Jersey et quelques régions limitrophes) et les territoires apparentés, telle la Pennsylvanie. Un auteur à succès et intellectuel américain influent comme Russell Shorto, par exemple, a même fait du thème de la tolérance néerlandaise la clé de son interprétation de l'histoire des Pays-Bas et de la Nouvelle Néerlande et partant, de la spécificité de l'histoire américaine dans le contexte retrouvé du pluralisme de ses origines.

4 L'importance politique de ce véritable dogme de la liberté religieuse américaine a donné au thème de la tolérance un caractère explosif et l'a en même temps dépouillé de sa dimension historique. Dans toute cette littérature contemporaine, la liberté religieuse parait comme un fait primordial, fondateur de la société américaine des origines. L'ouvrage d'Evan Haefeli s'inscrit pleinement dans ce débat sur les origines néerlandaises de la liberté religieuse aux États-Unis, mais il y adopte délibérément une position d'historien critique. L'auteur y fournit une synthèse systématique, fine et originale qui tourne autant autour de l'histoire des idées et des pratiques religieuses, culturelles et sociales qu'autour des termes et des présupposés mêmes de ce débat et des notions de liberté et tolérance avancées, tout en plaçant le développement de la tolérance dans un contexte atlantique et en confrontant systématiquement l'ancien et le nouveau monde. Dans la Hollande même, l'attitude envers la liberté religieuse était le résultat d'une confrontation, sinon d'une négociation constante entre deux factions publiques. D'une part le milieu commercial et colonial d'esprit républicain et favorable à la liberté de conscience qui avait été inscrite dans la charte de fondation de la République (les articles d'union d'Utrecht de 1579) et permettait l'admission tacite de dissidents religieux. D'autre part l'Église réformée, ses membres et sympathisants, incluant une partie non négligeable de l'élite politique, négociante et sociale, voire les directeurs mêmes de la colonie, qui pour des raisons diverses insistaient sur l'unité confessionnelle du pays sous l'égide de l'Église publique et rejetaient tout pluralisme, aussi bien formel qu'informel.

5 Après avoir esquissé ce paysage pluriel aux contours changeants et constamment traversés de tensions entre les groupes au pouvoir, l'auteur examine l'évolution de la liberté religieuse dans le territoire concerné en dix chapitres aux titres aussi courts que précis et évocateurs. Il ouvre ses analyses par un exposé fort bien structuré autour de la notion de la tolérance hollandaise (en anglais tolerance), c'est-à-dire ses définitions 
parmi les historiens récents, les idées et principes qu'ils y attribuent. Ensuite, il se penche successivement sur la connivence (la forme courante de l'accommodement pluriconfessionnel dans les territoires néerlandais de part et d'autre de l'océan), la toleration (la pratique formelle d'admission publique de dissidents, assez rare), les nonchrétiens (les indigènes, certains groupes de noirs, les Juifs, les musulmans), Babel (l'attitude envers le nombre croissant de confessions importées, tels les luthériens allemands combattus par Stuyvesant), la liberté de conscience (mise au défi par l'apparition de nouveaux groupes de croyants faisant du prosélytisme public, tels les quakers), l'Église publique (en particulier son intervention dans la formule du rituel baptismal en 1658), les frontières (permettant aux catholiques, quakers et autres non réformés de profiter de la proximité de co-religionnaires dans les territoires voisins comme l'éphémère colonie suédoise luthérienne, le Maryland catholique, ou la Pennsylvanie, pour conforter leur existence), le radicalisme libertaire (les mennonites, l'inspiration de Spinoza et Van den Ende, l'éphémère communauté de Plockhoy), enfin la conquête anglaise scellée en 1674 par le Traité de Westminster qui, sans mettre fin à la culture religieuse d'origine néerlandaise, n'en eut pas moins pour conséquence que le modèle anglais de gestion de la diversité religieuse l'emporta et sut s'inscrire pour quelques siècles dans la réalité socioreligieuse de ces États. Haefeli conclut que le visage final de la liberté religieuse en Amérique néerlandaise était autant le résultat des hasards et des vicissitudes politiques que de la colonisation dans le pays mère du conquérant anglais ou que des évolutions socioreligieuses dans l'ancien pays mère néerlandais.

Certains éléments de cette évolution, peu connus hors de l'Amérique, reçoivent un traitement approfondi. Je n'en relève que la fameuse Flushing Remonstrance de 1657 (la Remontrance de Flessingue, rédigée dans la petite ville de ce nom sur Long Island par les quakers nouvellement établis), qui passe maintenant pour la première grande déclaration des principes de liberté religieuse par les colons anglais eux-mêmes en territoire néerlandais. Contrairement aux opinions prévalant aussi bien parmi les protestants que les catholiques, les pétitionnaires soutenaient que ce n'était pas l'erreur doctrinale qui était le véritable problème mais la persécution de ceux qui cherchaient à obéir directement à la loi divine. Ils redéfinissaient ainsi les termes mêmes de la tolérance d'une façon qui à long terme allait profondément marquer la vie religieuse américaine.

7 L'auteur corrige dans cette étude exemplaire l'image simplifiée d'une tolérance globale d'origine hollandaise qui s'opposait aux tendances monoconfessionnelles $\mathrm{du}$ colonisateur anglais ou français. En effet, si les rapports néerlando-français dans la colonie, limitrophe du Canada français, n'ont jamais reçu toute l'attention qu'ils méritent, ils étaient certainement fréquents, les missions jésuites étaient bien connues des colons néerlandais, et un jésuite persécuté par les indigènes comme le martyr Isaac Jogues a laissé de son séjour sous la protection des Hollandais à la Nouvelle Amsterdam un saisissant témoignage qui compte parmi les documents les plus cités sur la diversité religieuse et la pratique de la tolérance. Cette étude vient à point nommé pour relancer la recherche sur la tolérance dans une perspective proprement historique et socioreligieuse. Elle met au défi les vieux poncifs monolithiques dont la société américaine continue de se nourrir, changeant la référence anglaise tout simplement pour les supposées vertus hollandaises. 